\title{
SELEÇÃO E APLICAÇÃO DE UM BIOSSURFACTANTE NA DESESTABILIZAÇÃO DE EMULSÕES ÓLEO-ÁGUA VIA FLOTAÇÃO POR AR DISSOLVIDO
}

\author{
F. C. P. ROCHA E SILVA ${ }^{1}$, N. M. P. ROCHA E SILVA' ${ }^{2}$, A. E. MOURA ${ }^{3}$, R. G. \\ ALMEIDA $^{4}$, J. M. LUNA ${ }^{4}$, V. A. SANTOS ${ }^{4}$, L. A. SARUBBO ${ }^{4}$ \\ ${ }^{1}$ Departamento de Biotecnologia Industrial (Renorbio), Universidade Federal Rural de \\ Pernambuco \\ ${ }^{2}$ Departamento de Engenharia Química, Universidade Federal de Pernambuco \\ ${ }^{3}$ Centro de Tecnologia e Geociências, Universidade Federal de Pernambuco \\ ${ }^{4}$ Centro de Ciências e Tecnologia, Universidade Católica de Pernambuco \\ E-mail para contato: padilha.nanda@gmail.com
}

RESUMO -A separação gravitacional de emulsões formada entre água do mar e derivados de petróleo é de grande interesse para solucionar casos de derramamentos. Nesse sentido, os processos físico-químicos dentre eles a flotação por ar dissolvido (FAD), são bastante eficazes na separação óleo/água. Os surfactantes têm se mostrado como uma alternativa eficaz na separação de líquidos imiscíveis, assim, quatrobiossurfactantesforam obtidos através de diferentes microrganismos visando promover a desestabilização de emulsões com óleo motor em água do mar e água destilada. A taxa de desestabilização foi determinada, sendo o melhor resultado obtido para o biossurfactante de Candidasphaericacultivada em meio de baixo custo. A utilização dessa biomolécula elevou a eficiência de separação do protótipo de FAD de $80,0 \%$ para $98,0 \%$. Assim, pode-se concluir que o uso de biossurfactantes representa uma alternativa promissora na remediação de ambientes contaminados com derivados de petróleo.

\section{INTRODUÇÃO}

Desastres por derramamento de óleos são cada vez mais frequentes, sendo necessário apresentar soluções para minimizar os impactos causados no meio ambiente (Silvaet al., 2009). Particularmente, a poluição causada pelo petróleo é bastante tóxica para os animais marinhos e para as aves migratórias, além de prejudicar a população que vive no litoral das áreas atingidas (Gonziniet al., 2010).

Surfactantes constituem uma classe de compostos químicos importantes e que são muito utilizados em diversos setores industriais, destacando-se pela utilização para remoção de poluentes oleosos (Santoset al., 2013). Entretanto, a preocupação ambiental com o uso de produtos com padrões ecologicamente corretos vem aumentando, dessa maneira, é necessária a procura por surfactantes de origem natural, sendo estes denominados de biossurfactantes (Rufinoet al., 2014).

Os surfactantes tendem a se dispersar nas interfaces entre as fases fluídas com diferentes graus de polaridade óleo/água e água/óleo (Nitschke e Pastore, 2002). 
Os biossurfactantes são compostos de origem microbiana que exibem propriedades surfactantes, isto é, diminuem a tensão superficial e aumentam a capacidade de emulsificação/desemulsificação (Lunaet al., 2013). Esses bioprodutos são considerados sustentáveis devido ao alto grau de degradabilidade e baixa toxicidade (Rocha e Silvaet al., 2013).

Em paralelo ao desenvolvimento biotecnológico através dos surfactantes microbianos, o processo de separação por flotação está sendo proposto e utilizado como uma técnica limpa e eficaz para remoção de óleos e graxas, sendo necessário apenas o uso de ar para produção de microbolhas, promovendo a separação óleo/água. O biossurfactantepoderá auxiliar a remoção do óleo, deixando a água livre de poluição (Mulliganet al., 2001).

Este trabalho tem como objetivo analisar o comportamento de umbiossurfactante na desestabilização de emulsões óleo-água via flotação por ar dissolvido.

\section{MATERIAIS E MÉTODOS}

\subsection{Micro-organismo}

Diferentes micro-organismos foram utilizados para a produção dos biossurfactantes, sendo eles: a bactéria Pseudomonascepacia (CCT 6659) e as levedurasCandidalipolytica(UCP 0988)e Candidasphaerica(UCP 0995). Todos os microorganismos estão depositados no Banco de Culturas do Núcleo de Pesquisa em Ciências Ambientais (NPCIAMB) da Universidade Católica de Pernambuco.

\subsection{Meio de Cultivo e Condições de Produção do Biossurfactante}

Biossurfactante de Pseudomonascepacia: meio mineral descrito por Dubey e Juwarkar (2001), acrescido de $2 \%$ óleo de fritura (residual) e $2 \%$ de milhocina, durante 144 horas de cultivo, sob agitação de $250 \mathrm{rpm}$ e um inóculo de $10^{7}$ U.F.C./mL.

Biossurfactante deCandidalipolytica 1 : meio mineral suplementado com $6 \%$ de borra de óleo de soja e $1 \%$ ácido glutâmico, durante 72 horas de cultivo, sob agitação de 200 rpm e um inóculo de $10^{8}$ U.F.C./mL.

Biossurfactante deCandidalipolytica2: meio mineral contendo gordura animal $5 \%$ e milhocina $2,5 \%$, durante 144 horas de cultivo, sob agitação de $200 \mathrm{rpm}$ e um inóculo de $10^{4}$ U.F.C./mL.

Biossurfactante deCandidasphaerica: água destilada acrescida de 9\% de borra de óleo de soja e $9 \%$ de milhocina, durante 144 horas de cultivo, sob agitação de $200 \mathrm{rpm}$ e um inóculo de $10^{4}$ U.F.C./mL.

Todas as fermentações foram realizadas em frascos de Erlenmeyer e submetidas à agitação em shaker orbital. 


\subsection{Determinação da Tensão Superficial}

A tensão superficial foi medida a partir do líquido metabólico livre de células em tensiômetro KSV Sigma 70 (Finland) utilizando-se o anel de NUOY.

\subsection{Preparação de Emulsões com Óleo Motor}

Para o teste de desemulsificação, $2 \mathrm{~mL}$ do líquido metabólico livre de células contendo cada biossurfactante foi adicionado a tubos graduados contendo $18 \mathrm{~mL}$ da emulsão de óleo de motor com água destilada e água do mar na proporção de $1: 1(\mathrm{v} / \mathrm{v})$. O branco contendo $2 \mathrm{~mL}$ do meio de produção estéril foi usado, bem como um tubo contendo apenas a emulsão óleo de motor/água. Os tubos foram, então, deixados em repouso à temperatura ambiente. A alteração do volume da fase aquosa foi registrada após 24 horas. O desempenho da desemulsificação também foi avaliado, calculando-se a taxa de desemulsificação.

\subsection{Descrição Sucinta do Protótipo Piloto de FAD}

O protótipo de FAD (Figura 1), em escala piloto, foi confeccionado em acrílico a fim de permitir a visualização de boa parte dos fenômenos fluidodinâmicos.

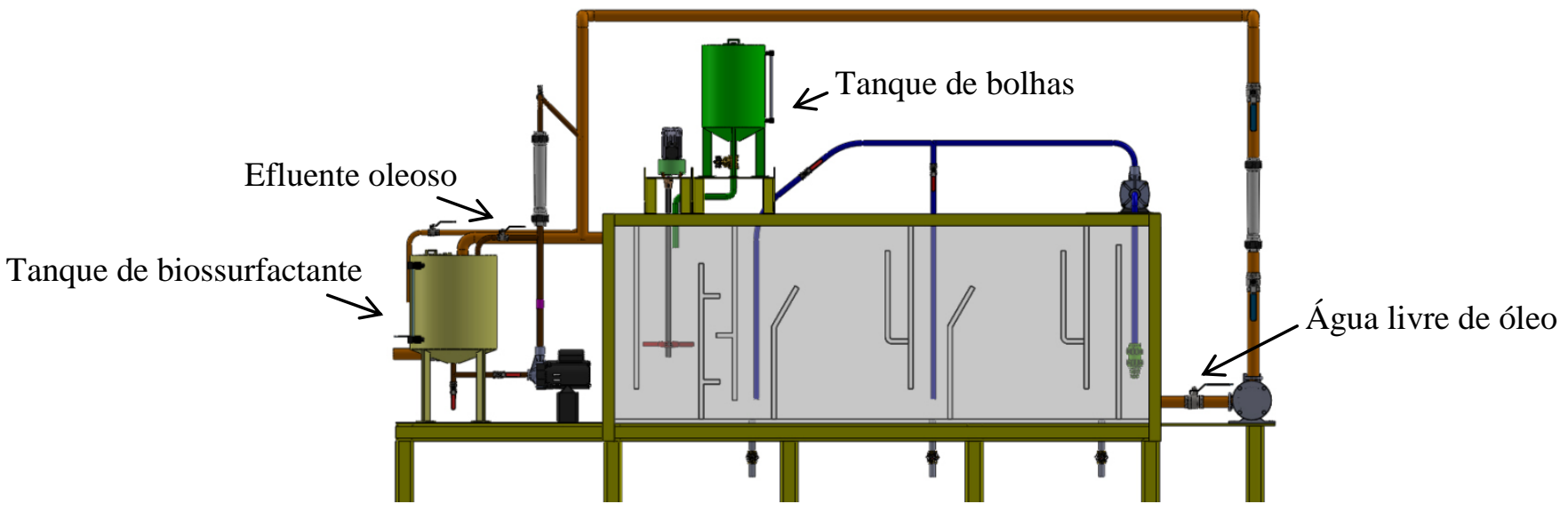

Figura 1 - Esquema tridimensional do sistema FAD em escala piloto

Duas câmaras, dispostas em série, sequenciam as antecâmaras e processam o afluente. Em ambas as câmaras as gotículas de óleo que formam uma emulsão com a água entram em contato com microbolhas de ar, formando partículas dispersas com densidade média menor que a da água e são flotadas, e desta maneira a espuma oleosa formada pode ser retirada, deixando a água livre de óleo ao final do processo.

\subsection{Planejamentos experimentais}

Inicialmente, foi aplicado um DCCR (Delineamento Composto Central Rotacional) do tipo $2^{2}$ para definir as condições operacionais do protótipo FAD. As variáveis independentes foram codificadas em 5 níveis $(-2,-1,0,+1,+2)$ proporcionando a execução de 12 experimentos. Os valoresde variáveis independentes utilizadas para construir um gráfico de superfície de resposta (RSM) estão dispostos na Tabela 1. 
Tabela 1 - Valores experimentais e níveis das variáveis independentes para eficiência de separação do sistema piloto FAD com adição de biossurfactante

\begin{tabular}{lccccc}
\hline \multicolumn{1}{c}{ Fatores } & $\mathbf{- 1 , 4 1}$ & $\mathbf{- 1 , 0 0}$ & $\mathbf{0 , 0 0}$ & $\mathbf{+ 1 , 0 0}$ & $\mathbf{+ 1 , 4 1}$ \\
\hline $\begin{array}{l}\text { Razão entre vazões de água e } \\
\text { ar de microbolhas } \cdot 10^{3},\left(X_{1}^{\prime}\right)\end{array}$ & 0,30 & 0,50 & 1,00 & 1,5 & 1,71 \\
$\begin{array}{l}\text { Razão entre vazões de } \\
\text { biossurfactante e de água na } \\
\text { alimentação } \cdot 10^{4},\left(X_{2}^{\prime}\right)\end{array}$ & 0,56 & 0,70 & 1,05 & 1,40 & 1,54 \\
\hline
\end{tabular}

\subsection{Efluente Sintético Oleoso e Dosagem de Biossurfactante}

O efluente sintético utilizado nos experimentos foi produzido combinando-se as vazões de alimentação de água e de óleo no protótipo piloto. A quantidade de óleo adicionada foi constante na concentração de $50 \mathrm{ppm}$.A dosagem de biossurfactante foi proporcional à quantidade de óleo, sendo adicionado 20 ppm do líquido metabólico livre de células.

\section{RESULTADOS E DISCUSSÃO}

\subsection{Determinação das tensões superficiais}

A tensão superficial é utilizada como critério primário para identificar microrganismos produtores de biossurfactantes(Youssefet al., 2004).Neste sentido, foram produzidos quatrobiossurfactantes, a fim de analisar a redução da tensão superficial do meio de cultivo (Tabela 2).

Tabela 2 - Valores de tensão superficial obtidos ao término da fermentação para os diferentes micro-organismos testados

\begin{tabular}{cc}
\hline $\begin{array}{c}\text { Microrganismo produtor } \\
\text { de biossurfactante }\end{array}$ & $\begin{array}{c}\text { Tensão Superficial } \\
(\mathbf{m N} / \mathbf{m})\end{array}$ \\
\hline Candidalipolytica (1) & 25,0 \\
\hline Candidalipolytica (2) & 27,75 \\
\hline Candidasphaerica & 25,0 \\
\hline Pseudomonascepacia & 27,57 \\
\hline
\end{tabular}

De acordo com a literatura, a maioria dos biossurfactantes produzidos por bactérias tem demonstrado capacidade de reduzir a tensão superficial da água de $72 \mathrm{mN} / \mathrm{m}$ para valores que variam em torno de 32-27 mN/m (Silvaet al., 2010). Resultados semelhantes e igualmente satisfatórios foram obtidos pelas espécies de leveduras $C$. sphaericae $C$. lipolytica (Lunaet al., 2013; Rufinoet al., 2011). 
Esta capacidade de reduzir a tensão superficial é uma das propriedades mais importante dos surfactantes em geral, tendo em vista que esta característica permite que haja interação nas interfaceslíquido-ar e líquido-líquido, facilitando o processo de desemulsificação.

\subsection{Testes de Desemulsificação}

Os experimentos de desemulsificação foram conduzidos de acordo com Liuet al.(2009). Sendo estes realizados para os quatro biossurfactantes, onde os resultados estão dispostos na Tabela 3.

Tabela 3 - Taxa de desemulsificação (\%) para as emulsões com óleo motor após 24 horas

\begin{tabular}{c|c|c}
\hline \multirow{2}{*}{$\begin{array}{c}\text { Microrganismo produtor } \\
\text { de biossurfactante }\end{array}$} & \multicolumn{2}{|c}{ Tipo de emulsão } \\
\cline { 2 - 3 } & $\begin{array}{c}\text { Água destilada } \\
(\boldsymbol{\%})\end{array}$ & $\begin{array}{c}\text { Água do mar } \\
(\boldsymbol{\%})\end{array}$ \\
\hline Candidalipolytica (1) & 37,0 & 21,9 \\
\hline Candidalipolytica (2) & 27,3 & 26,9 \\
\hline Candidasphaerica & 38,8 & 40,6 \\
\hline Pseudomonascepacia & 0 & 0 \\
\hline
\end{tabular}

Na literatura, é comum encontrar estudos sobre o efeito da variação de $\mathrm{pH}$ nas emulsões estudadas, visando promover o aumento da eficiência de desemulsificação (Longet al., 2013; Coutinho et al., 2013). Para a faixa de pH analisada, entre 6,0 e 6,8, os resultados obtidos estão coerentes com os apresentados na literatura, tendo em vista que os biossurfactantes obtidos por Candidaapresentaram resultados superiores a $20 \%$ de taxa de desemulsificação para os ensaios com água destilada e água do mar.

Neste caso, também é possível observar que o biossurfactante de Pseudomonas não apresentou características desemulsificantes, sendo descartado o seu uso no protótipo piloto FAD.

Os diferentes resultados obtidos em relação à utilização de água destilada e água do mar podem ser atribuídos, principalmente, às forças iônicas presentes. Em função da presença de grupos hidrofílicos e hidrofóbicos na mesma molécula, os surfactantes tendem a se distribuir nas interfaces entre fases fluidas com diferentes graus de polaridade, o que torna $o$ comportamento de cada biossurfactante único.

\subsection{Eficiência de Separação Água-Óleo com a Adição de Biossurfactante}

A análise de variância dos dados experimentais gerados pelo protótipo piloto de FAD operando com a adição de biossurfactante deu origem à Tabela4.Todos os termos lineares e quadráticos apresentaram-se significância estatística dentro do intervalo de confiança de $95 \%$. Assim, é recomendada a adoção do modelo de previsão proposto pela Equação 1.

$$
Y_{1}=-202,0+163,2 \cdot X_{1}-78,8 \cdot X_{1}^{2}+369,0 \cdot X_{2}-144,3 \cdot X_{2}^{2}-12,8 \cdot X_{1} \cdot X_{2}
$$

Dessa maneira, o gráfico de superfície de resposta (Figura 2) foi obtido, onde nele está representado a eficiência de separação do processo de flotação da ordem de $98 \%$. 
Tabela 4 -Análise de variância (ANOVA) para o rendimento de separação do sistema piloto FAD com adição de biossurfactante

\begin{tabular}{cccccc}
\hline $\begin{array}{c}\text { Fonte de } \\
\text { variação }\end{array}$ & $\begin{array}{c}\text { Soma } \\
\text { Quadrática }\end{array}$ & $\begin{array}{c}\text { Grau de } \\
\text { Liberdade }\end{array}$ & $\begin{array}{c}\text { Média } \\
\text { Quadrática }\end{array}$ & F & P \\
\hline $\mathbf{X}_{\mathbf{1}}(\mathbf{L})$ & 120,448 & 1 & 120,448 & 131,398 & 0,001425 \\
$\mathbf{X}_{\mathbf{1}}(\mathbf{Q})$ & 2480,625 & 1 & 2480,625 & 2706,136 & 0,000016 \\
$\mathbf{X}_{\mathbf{2}}(\mathbf{L})$ & 2748,980 & 1 & 2748,980 & 2998,887 & 0,000013 \\
$\mathbf{X}_{\mathbf{2}}(\mathbf{Q})$ & 2002,225 & 1 & 2002,225 & 2184,245 & 0,000022 \\
$\mathbf{X}_{\mathbf{1}} \mathbf{x} \mathbf{X}_{\mathbf{2}}$ & 20,250 & 1 & 20,250 & 22,091 & 0,018220 \\
$\begin{array}{c}\text { Falta de } \\
\text { Ajuste }\end{array}$ & 201,197 & 3 & 67,066 & 73,163 & 0,002647 \\
$\begin{array}{c}\text { Erro } \\
\text { Experimental }\end{array}$ & 2,750 & 3 & 0,917 & & \\
Total SS & 6834,667 & 11 & & & \\
\hline
\end{tabular}

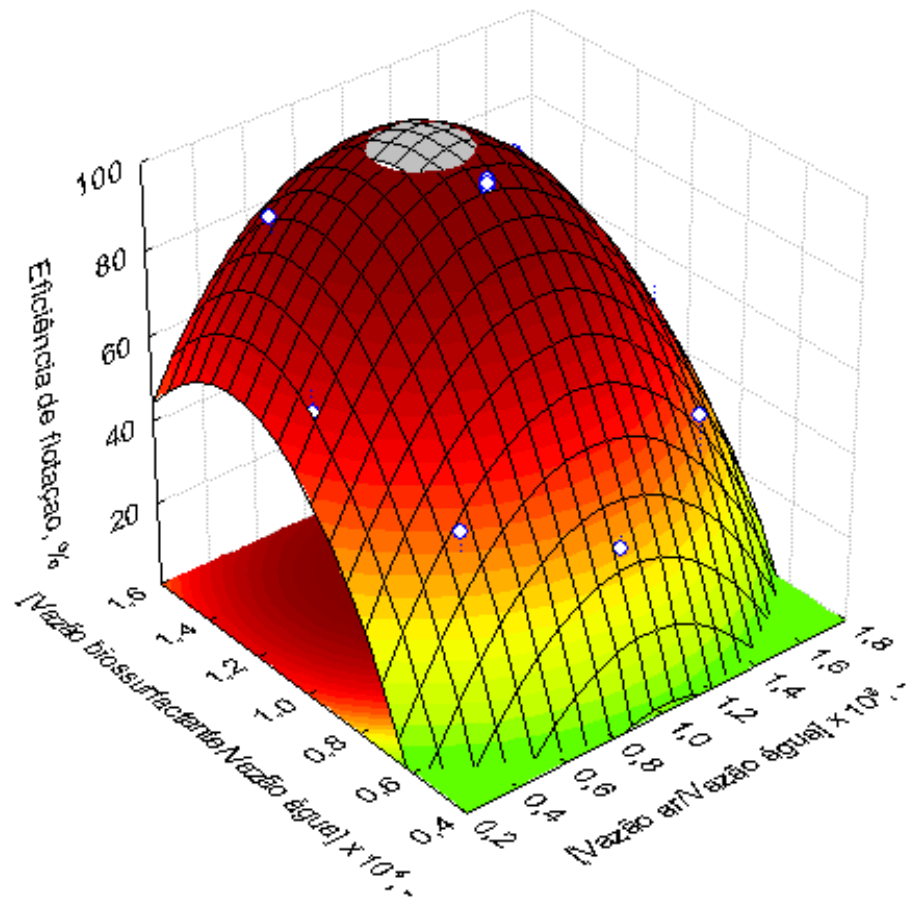

Figura 2 - Gráfico de superfície de resposta do efeito combinado de fatores observados quanto a eficiência de separação do sistema piloto FAD com adição de biossurfactante 


\section{CONCLUSÕES}

Os resultados obtidos indicam que o processo de flotação por ar dissolvido (FAD) com a adição de biossurfactante é bastante efetivo para o tratamento de águas oleosas, principalmente se houver contaminação por óleo motor, como no caso de Usinas Termelétricas.

Analogamente, a adoção de um surfactante de origem microbiana se mostra em vantagem frente aos surfactantes sintéticos, tendo em vista o seu caráter atóxico, estável, sustentável e de baixo custo, tendo em vista que utilizam-se resíduos industriais no processo fermentativo.

\section{AGRADECIMENTOS}

Os autores agradecem ao Centro de Gestão de Tecnologia e Inovação (CGTI), ao Programa de Recursos Humanos em Petróleo e Gás Natural da Petrobrás (PRH-28) e a Fundação de Amparo à Ciência e Tecnologia do Estado de Pernambuco (FACEPE).

\section{REFERÊNCIAS BIBLIOGRÁFICAS}

COUTINHO, J. O. P. A.; SIlVA, M. P. S.; MORAES, P. M.; MONTEIRO, A. S.; BARCELOS, J. C. C.; SIQUEIRA, E. P.; SANTOS, L. L. Demulsifyingproperties of extracellularproducts and cells of Pseudomonasaeruginosa MSJ isolatedfrompetroleumcontaminatedsoil. Biores.Technol. v.128, p.646-654. 2013.

DUBEY, K.; JUWARKAR, A. Distillery and curd whey wastes as viable alternative sources for biosurfactant production.W. J. Microb.Biotechnol, v. 17, p.61-69, 2001.

GONZINI, O.; PLAZA, A.; PALMA. D. I. L.; LOBO, M. C. Electrokinetic remediation of gasoil contaminated soil enhanced by rhamnolipids.J. of Appl. Eletroche. v. 40, p.1239$1248,2010$.

LIU, J.; HUANG, X. F.; LU, L. J.; XU, J. C.; WEN, Y.; YANG, D. H. Comparison between waste frying oils and paraffin as carbono source in the production of biodemulsifier by dietzia sp. S-JS-1. Biores.Technol. v.24, n. 100, p. 6481-9487, 2009.

LONG, X.; ZHANG, G.; SHEN, C.; SUN, G.; WANG, R.; YIN, L.; MENG, Q. Application of rhamnolipid as a novel biodemulsifier for destabilizing waste crude oil.Biores. Technol.. v.131, p.1-5. 2013.

LUNA, J.M.; RUFINO, R.D.; SARUBBO, L.A.; CAMPOS-TAKAKI, G.M.Characterization, surface properties and biological activity of a biosurfactant produced from industrial 
waste by Candida sphaerica UCP0995 for application in the petroleum industry. Collo.and Surf. B: Biointerfaces, V. 102, p. 202-209, 2013.

MULLIGAN, C. N.; YONG, R. N.; GIBBS, B. F. Surfactant-enhancedremediation ofcontaminatedsoil: a review. EngineeringGeology. n. 60, p. 371-380, 2001.

NITSCHKE, M.; PASTORE, G. M. Biossurfactantes: propriedades e aplicações. Quím. Nov. v. 25, p. 772-776, 2002.

ROCHA E SILVA, N. M. P.; RUFINO, R. D.; LUNA, J. M.; SANTOS, V. A.; SARUBBO, L. A. Screening of Pseudomonas species for biosurfactant production using low-cost substrates. Biocatal.andAgricul.

Biotechnol. http://dx.doi.org/10.1016/j.bcab.2013.09.005, 2013.

RUFINO, R. D.; LUNA, J. M.; CAMPOS-TAKAKI, G. M.; SARUBBO, L. A. Characterization and properties of the biosurfactant produced by Candida lipolytica UCP 0988. Eletro. J. ofBiotechnol. v. 17, p.34-38, 2014.

RUFINO, R. D.; LUNA, J. M.; FARIAS, C. B. B.; SANTOS, V. A.; SARUBBO, L. A. Biossurfactante de baixo custo utilizado na remoção de contaminantes ambientais derivados de petróleo. Simp.Nacion.deBioproc., 2011.

SANTOS, D. K. F.; RUFINO, R. D.; SANTOS, V. A.; SALGUEIRO, A. A.; SARUBBO, L. A. Syntesis and evalution of biosurfactant produced by Candida lipolytica using animal fat and corn steep liquor. J. of Petrol.Scien.and Eng. v. 12, p.1-32, 2013.

SILVA, S. N. R. L.; FARIAS, C. B. B.; RUFINO, R. D.; LUNA, J. M.; SARUBBO, L. A. Glycerol as substrate for the production of biosurfactant by Pseudomonas aeruginosa UCP0992. Collo.and Surf. B: Biointerfaces, v. 79, p.174-183, 2010.

SILVA, S. N. R. L.; SANTOS, D. K. F.; SILVA, A. F.; FARIAS, C. B. B.; LUNA, J. M.; CAMPOS-TAKAKI, G. M.; SARUBBO, L. A. Glicerina como substrato alternativo para produção de biossurfactantes In: IV Simposio de Microbiologia Aplicada, 2009, Rio Claro, SP. HolosEnvironm. 2009.

YOUSSEF, N. H.; DUNCAN, K. E.; NAGLE, D. P.; SAVAGE, K. N.; KNAPP, R. M.; MC INERNEY, M. J. Comparison of methods to detectbiossurfactantproductionbydiversemicroorganism. J. of MicrobMeth.v.56, p. 399$347,2004$. 